\title{
Green activists enlist penguins to save the world
}

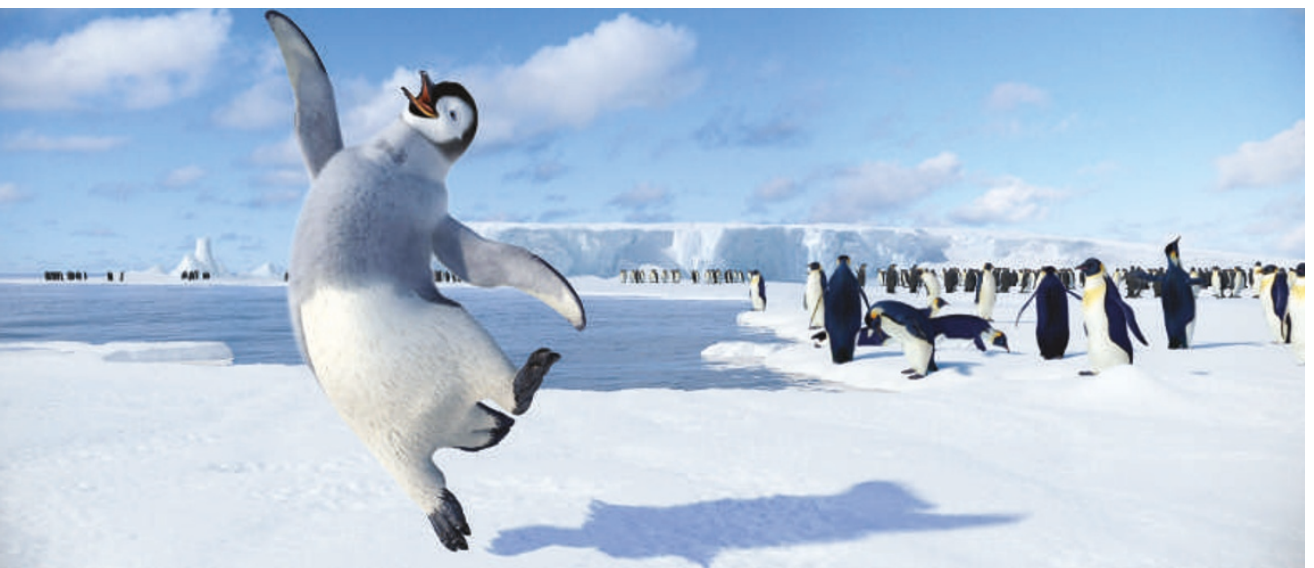

What if threatened species, instead of waiting for extinction, decided to charm humans into saving them? That's the plot of this winter's hit film, Happy Feet, in which emperor penguins score a total moratorium on Antarctic fishing thanks to their winsome tap-dancing routines. Environmental groups are using the film, and last year's equally popular documentary March of the Penguins, to push their messages - especially the dangers of increasing fishing in the Southern Ocean and climate change.
Mark Stevens, a campaign manager at the National Environmental Trust, sees Happy Feet as a way to boost audiences' environmental awareness. "It's a fun, gentle way to educate people about it. Whenever we get a chance, we like to talk about the facts behind the movie." In Happy Feet, the penguins' fish shortage is caused by humans. Stevens says that another source of food for some penguins is threatened in real life: "Fishing for krill is expected to increase dramatically in the next few years."
During the height of March of the Penguins' popularity, lawyers at another environmental group, the Center for Biological Diversity based in Tucson, Arizona, decided to ask the Environmental Protection Agency to list a dozen penguin species as endangered. They timed the move to the release of Happy Feet. "We scrambled to assemble and file the petition while the buzz around the movie was at its peak," says Brendan Cummings, an attorney with the group.

But all this animated advocacy has some US commentators up in arms, criticizing Happy Feet as propaganda by stealth. Conservative-leaning Fox News anchor Neil Cavuto called it an "animated Inconvenient Truth", referring to former US vice-president Al Gore's documentary on climate change, even though the film doesn't mention global warming directly. Many children's films have had environmental themes in the past few years (see 'Messages in movies').

Meanwhile the US Commission for the Conservation of Antarctic Marine Living Resources, although widely praised for setting sensible fishing quotas, is being pressured by various groups of environmentalists and scientists to consider more cautiously the whole Antarctic ecosys-

\section{Gravity probe falters}

Two unexpected effects are plaguing a quixotic satellite designed to measure a subtle effect of gravity. But project scientists say they are optimistic that they can still extract a significant finding from their data.

The problems have delayed results from the satellite, known as Gravity Probe-B, until spring 2007, according to project head Francis Everitt, a physicist at Stanford University in California.

Gravity Probe-B is designed to detect a tiny effect of gravity known as frame dragging. According to Einstein's general theory of relativity, a spinning mass such as the Earth drags space-time around it like a mixer dragging batter. Gravity Probe-B hoped to detect the effect with four almost perfectly spherical gyroscopes attached to a telescope. The telescope is trained on a guide star, and the gyros are set spinning. With the satellite aligned to the star, the drag should tilt the gyros off their axes by a minuscule amount, around 0.000011 degrees in a year.

Gravity Probe-B's journey from conception into orbit was unusually long. It began with modest funding from NASA in 1964 , but the high-precision instruments it required took around two decades to develop. The 1986 Challenger disaster further set back the launch of the probe, which was originally scheduled to fly aboard a space shuttle (see Nature 426, 380; 2003). After several near-cancellations, the satellite finally lifted off in April 2004. By then it had racked up a price tag of US\$700 million, and another project, Lageos, had become the first to measure the frame-dragging effect (see Nature 431, 958; 2004).

After an initial calibration phase, Gravity Probe-B took a year's worth of data,

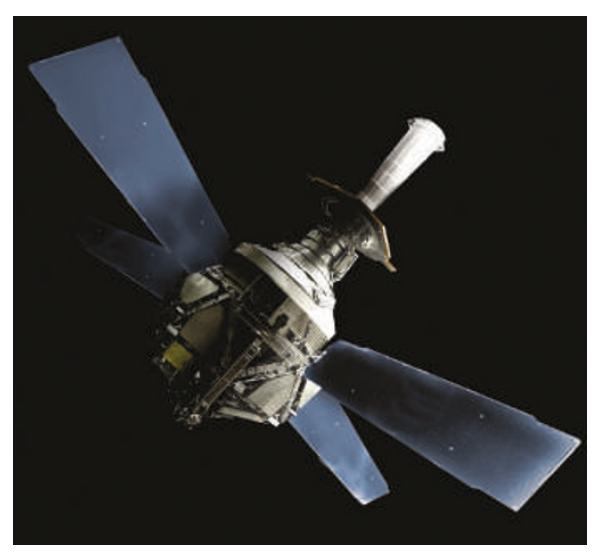

Gravity effects: wobbles and torques are hampering the interpretation of space data.

completing operations in September 2005. Results were expected by last summer, but the announcement never came.

Nature has learned that this is because two unanticipated effects are clouding the team's frame-dragging result. The first is a slight, 


\section{Messages in movies}

Children's films containing environmental messages are nothing new. Here are a few examples.

\section{Ice Age 2: The Meltdown}

Pleistocene creatures flee melting ice in this slapstick romance. The melting is caused by local volcanism, but the first line in the film - "This global warming is killing me!" - hints at a climate-change subtext.

Over the Hedge A family of forest critters awake from hibernation one spring to find half the forest overtaken by suburban development. To find food they must enter human territory to scavenge while avoiding death at the hands of the "freaky pink primates".

\section{March of the Penguins This} documentary about emperor penguins lacks the feeling of impending doom present in Happy Feet. Tracking their annual journey to breed in the harsh Antarctic terrain, the film focuses on the life-affirming wonders of nature while steering clear of environmental messages. But packed with the DVD is a short film about research on the effects of climate change on the birds.

Cars Hot-shot racecar Lightning McQueen finds a new friend in Sally Carrera, who laments the construction of the interstate that has cut through the beautiful desert landscape. But the implications of a world of cars for the climate are not explored. tem, including penguins, when setting fishing restrictions in the Southern Ocean. One major effort is the Antarctic Krill Conservation Project, in which the National Environmental Trust and Pew Charitable Trusts are both involved.

David Ainley, an ornithologist and adviser for ecological consultants H. T. Harvey \& Associates, spoke to Nature via satellite phone from Ross Island in Antarctica, and understandably hasn't seen Happy Feet yet. He's less worried about krill than about Antarctic toothfish (Dissostichus mawsoni) further up the food chain, but adds that the combined effect of climate change and human intervention on the food web are complex and need more research.

Even Ainley's perspective is likely to be more widely disseminated thanks to penguinmania. He's producing a film on climate change and Adelie penguins, which he hopes to distribute to schools. "Obviously," he says, "we're banking on penguins for the wide distribution of our educational DVD."

Katie McGoldrick and Emma Marris circular wobble created by a combination of tiny imperfections in the gyroscopes and a gradual slowing of their spinning. Gravity Probe-B scientists anticipated the wobble, but their calculations had ruled out the possibility that its period would change. "But it happened," says Everitt. "Nature decides what it wants to do."

The second problem is a torque on the four gyros. The twisting force came about when the satellite's telescope occasionally slipped off the guide star, and it seems to be related to tiny electric fields between various components of the probe. The team didn't discover the effect until after the satellite finished taking data, but are now trying to disentangle it from the result. The problem appeared quite serious during the summer, but Everitt says the team is now working on a "very elegant" solution.

It is unclear how the problems will affect the mission's result. "The Gravity Probe-B team is playing its cards very close to its chest," says Bernard Schutz of the Max-
Planck Institute for Gravitational Physics in Potsdam, Germany. "Nobody outside the project knows whether they can understand and measure the effects well enough to reach their original objective."

That objective was to measure the framedragging effect to within about $1 \%$, which would be ten times more accurate than the Lageos result. Clifford Will, a physicist at Washington University in St Louis, who chairs NASA's scientific advisory board for the project and has been briefed by the team, says he is optimistic that there will be some sort of result. "But will it be what they promised NASA? I don't know."

Everitt says that his team will announce a definitive result at the American Physical Society meeting in April 2007. He says he is still worried about whether they can produce a meaningful finding: "I don't think you should be relaxed on $\$ 700$ million," he says. "But I wouldn't have agreed to give a talk if I wasn't reasonably confident."

Geoff Brumfiel 